\title{
Simulation of the Adsorption and Release of Large Drugs by ZIF-8
}

Yaicel G. Proenza,* Ricardo L. Longo

Departamento de Química Fundamental, Universidade Federal de Pernambuco, Cidade Universitária, Recife-PE, 50740-560, Brasil. Fax: +55 812126 8442. Tel.: +55 8121267459.

*Corresponding author: ygeproenza@gmail.com

\section{SUPPORTING INFORMATION}

Figure S1. Atom labels of the molecular models used in the simulations. ...................................2

Figure S2. Structure of the ZIF-8P model.........................................................................2

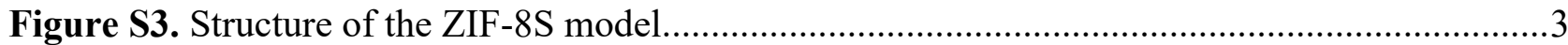

Figure S4. Drawing of the ZIF-8S structure showing the volume of the inner pores (yellow spheres), which are blocked for the drugs and allowed for the solvents.

Figure S5. Vapor-liquid equilibrium (VLE) curves for water and methanol simulated with the Gibbs ensemble Monte Carlo (GEMC) approach. .............................................................................

Figure S6. Radial distribution functions (RDF) for methanol and water....................................4

Figure S7. Powder X-ray diffraction (PXRD) pattern and pore size distribution (PSD) curves of the ZIF-8 framework, calculated in this work for the ZIF-8P model.

Figure S8. Total internal energy, U; and host-adsorbate energy, UнA; in the adsorbed phase along the $\mathrm{MC}$ cycles in GCMC calculations..

Figure S9. Snapshots of stable configurations of ZIF-8P loaded with the drugs, taken from simulation of the adsorption on methanol solution at 0.30 mole fraction.

Figure S10. Snapshots of stable configurations of ZIF-8S loaded with the drugs, taken from simulation of the adsorption on methanol solution at 0.30 mole fraction.

Table S1. Summary of the crystallographic data of ZIF-8 used to construct the ZIF-8P and ZIF-8S models for the computer simulations.

Table S2. Force filed parameters ( $\sigma$ and $\varepsilon$ ) and partial charges $(q)$ used to model the non-bonded interactions of the frameworks, drugs and solvents.

Table S3. Results from GCMC simulations of the adsorption of the pure drugs and solvents in the ZIF-8P structure.

Table S4. Mole fractions $x$ of the drug+methanol solutions used for simulating the adsorption of the drugs in the liquid phase via GEMC simulations

Table S5. Results from GEMC simulations of the adsorption of the drugs onto ZIF-8P from solution at several mole fractions $x(0.01$ to 0.30$)$

Table S6. Results from GEMC simulations of the adsorption of the drugs onto ZIF-8S from methanol solution at mole fraction 0.30 .

Table S7. Results from GEMC simulations of the desorption of the drugs from the ZIF-8P and ZIF$8 \mathrm{~S}$ models.

Equation S1. Expression used to calculate the enthalpy of adsorption from simulations. 10 


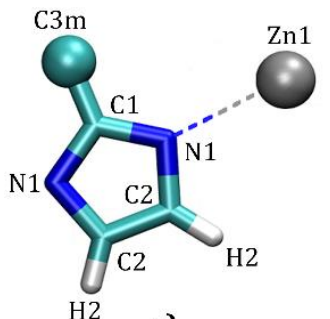

a)
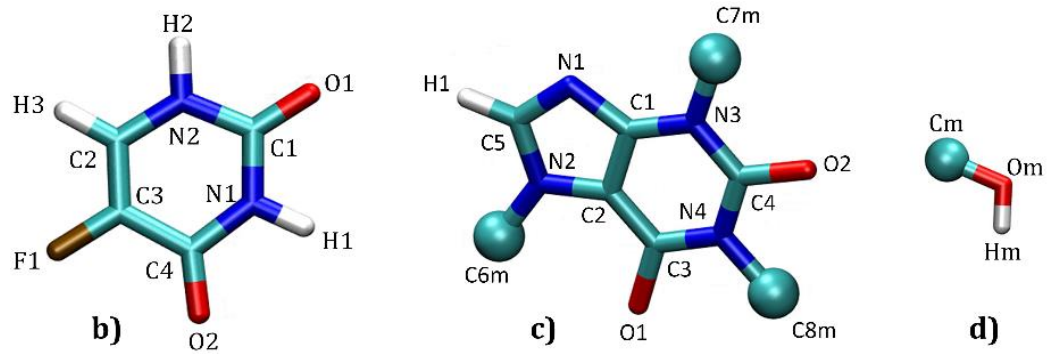

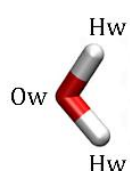

e)

Figure S1. Atom labels of the molecular models used in the simulations for a) the ZIF-8 framework; the drugs b) $5 \mathrm{FU}=5$-fluorouracil and c) $\mathrm{CAF}=$ caffeine; the solvents d) $\mathrm{MET}=$ methanol and e) WAT $=$ water. The carbon atoms are shown in cyan, nitrogen in blue, oxygen in red, fluorine in ochre, zinc in silver (in the ZIF8 moiety) and hydrogen in white. The cyan spheres represent methyl groups $\left(-\mathrm{CH}_{3}\right)$ as a carbon-type pseudoatom with mass $15.035 \mathrm{amu}$.
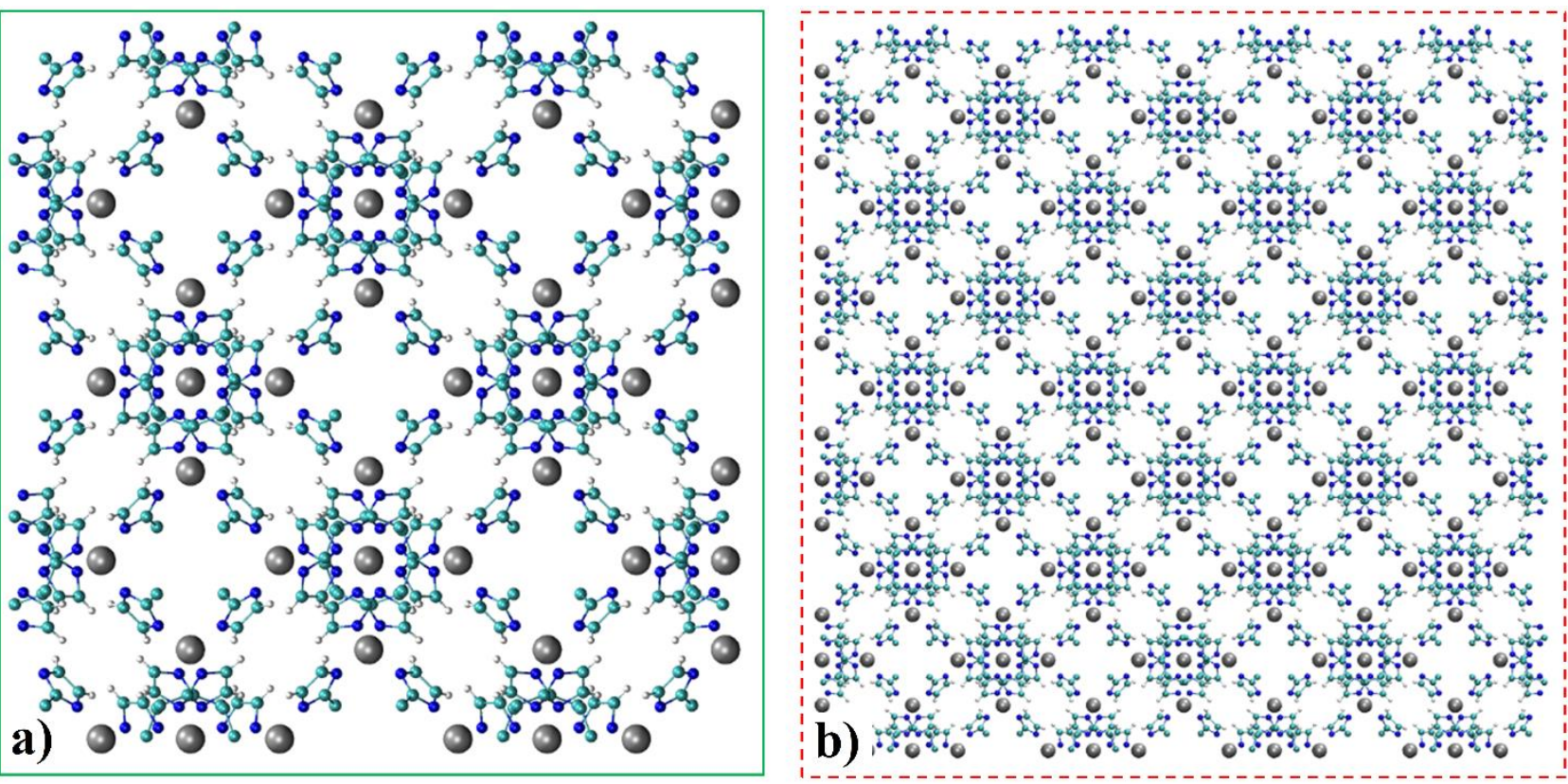

Figure S2. Structure of the ZIF-8P model. a) The basic unit cell constructed a cubic cell of $33.982 \AA$ edges from a $2 \times 2 \times 2$ ZIF- 8 cell. b) Illustration of the structure under periodic conditions employed in the simulations. The CIF-file is available upon request to the authors. The carbon atoms are shown in cyan including the $-\mathrm{CH}_{3}$ pseudoatom of the imidazolate fragments, nitrogen in blue, zinc in silver (biggest spheres), and hydrogen in white. See Figure S1a for specific atom labels. 

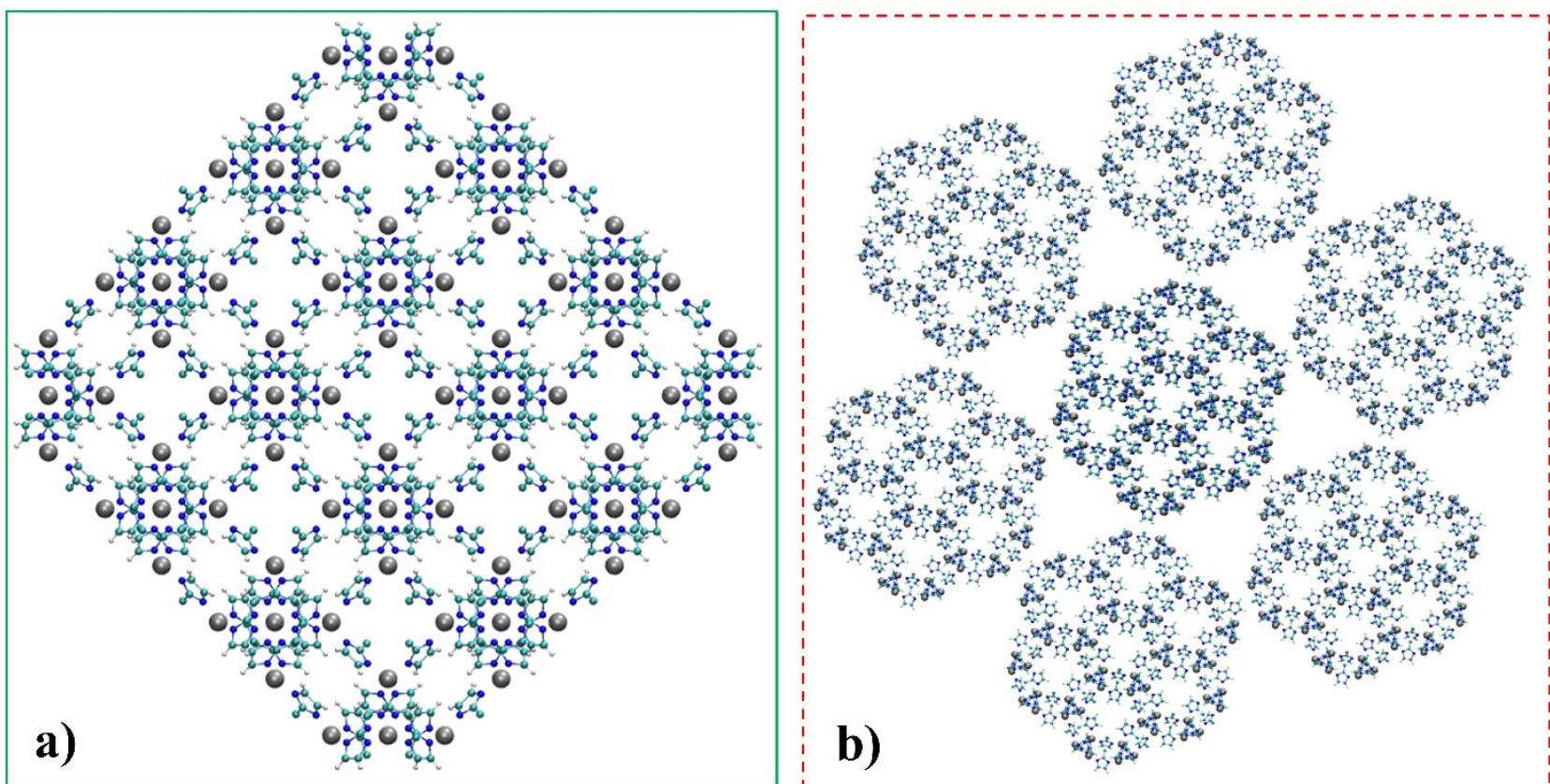

Figure S3. Structure of the ZIF-8S model. a) The basic unit cell constructed a cubic cell of $61.964 \AA$ edges from an initial $4 \times 4 \times 6$ ZIF- 8 unit cell and then dropping the outermost imidazolate linkers such that the final structure matches the hexagonal three-dimensional shape of the ZIF-8 crystals. b) Illustration of the structure under periodic conditions employed in the simulations. The CIF-file is available upon request to the authors. The carbon atoms are shown in cyan including the $-\mathrm{CH}_{3}$ pseudoatom of the imidazolate fragments, nitrogen in blue, zinc in silver (biggest spheres), and hydrogen in white. See Figure S1a for specific atom labels, with only detail that uncoordinated $\mathrm{Zn}$ atoms on the surface were labeled as $\mathrm{Zn} 2$ to differentiate from $\mathrm{Zn} 1$.
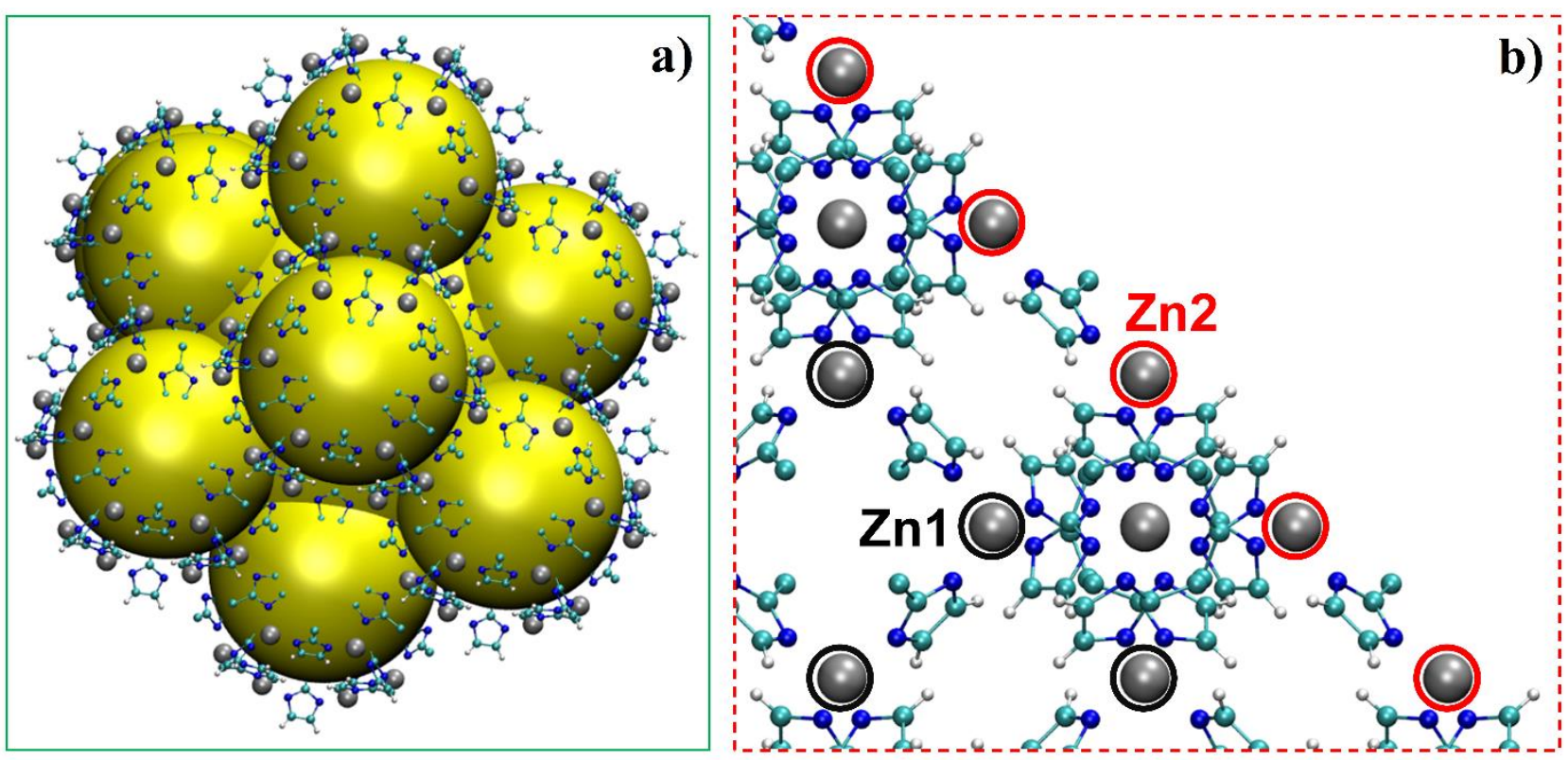

Figure S4. a) Drawing of the ZIF-8S structure showing the volume of the inner pores (yellow spheres), which are blocked for the drugs and allowed for the solvents. b) Snapshot of the ZIF-8S surface signalizing some Zn atoms with incomplete tetrahedral coordination (in red circles, named $\mathrm{Zn} 2$ ), and the common $\mathrm{Zn} 1$ atoms fully coordinated with the imidazolate linkers (in black circles). 

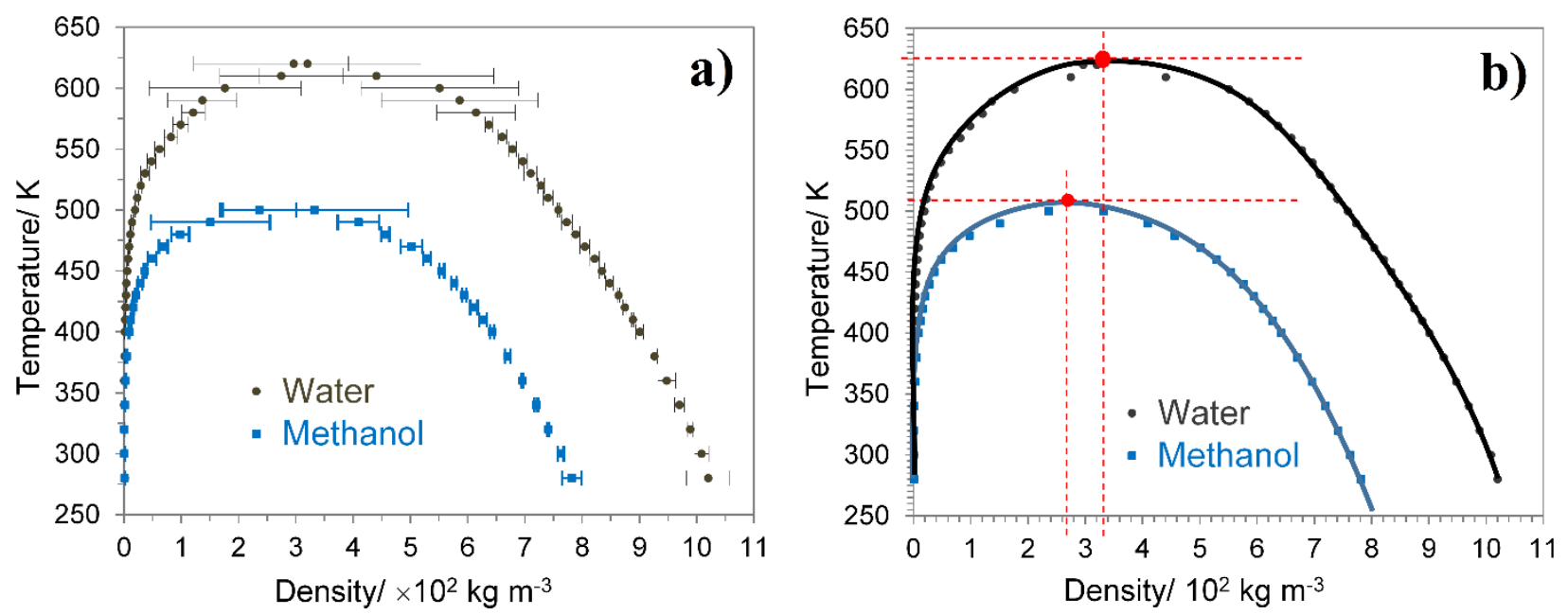

Figure S5. a) Vapor-liquid equilibrium (VLE) curves for water and methanol simulated with the Gibbs ensemble Monte Carlo (GEMC) approach with two $30 \times 30 \times 30 \AA$ simulation boxes, one for the vapor $\left(\mathrm{S}_{0}\right)$ and the other for the fluid phase $\left(S_{1}\right)$. The systems were 900 and 402 molecules of water and methanol, respectively, equally distributed in the two boxes. The data were collected from 500000 GEMC moves after previous 50000 NVT-MC cycles for initialization. b) Interpolations of the VLE points and estimates of the maximum on each curve, from which the following approximated critical properties were extracted: $T_{c} \cong 508 \mathrm{~K}$ and $\rho_{c} \cong 270$ $\mathrm{kg} \mathrm{m}^{-3}$ for methanol and $T_{c} \cong 625 \mathrm{~K}$ and $\rho_{c} \cong 330 \mathrm{~kg} \mathrm{~m}^{-3}$ for water.
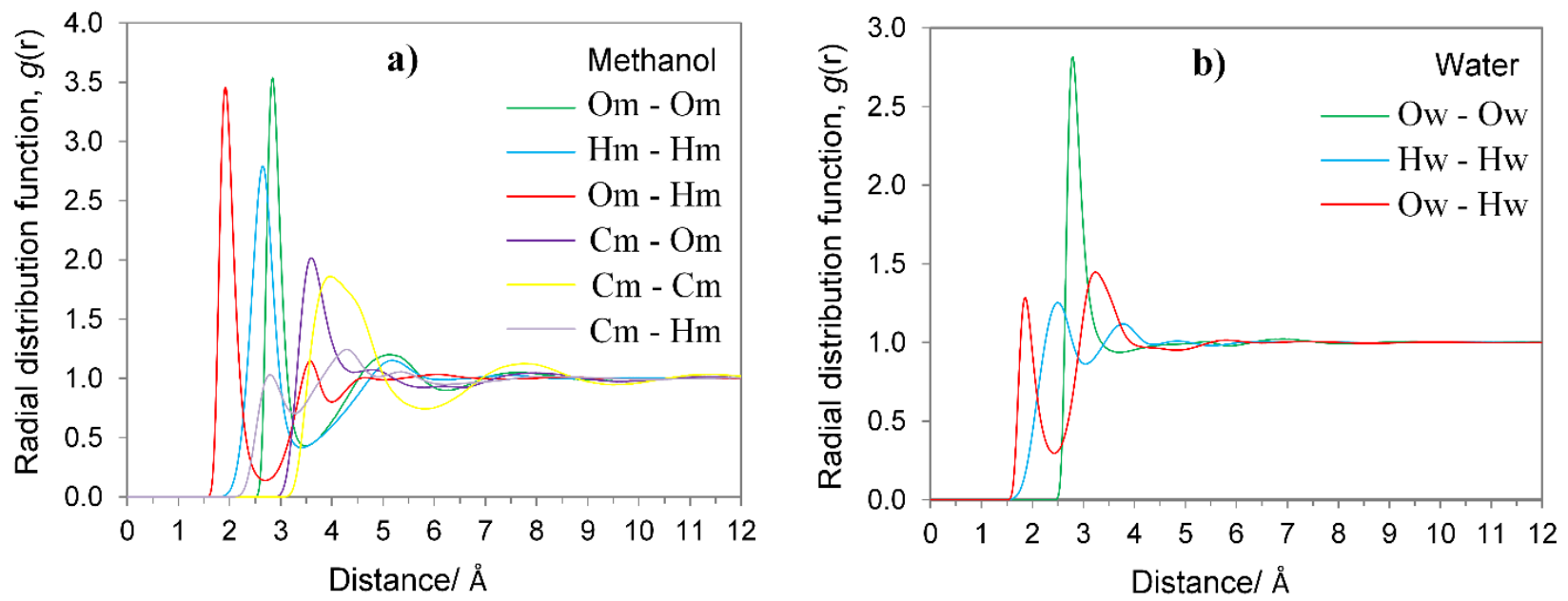

Figure S6. Radial distribution functions (RDF) for atom pairs of the solvents, obtained from NVT-MD simulations at $298 \mathrm{~K}$ of a) methanol and b) water, in separated $25 \times 25 \times 25 \AA$ simulation boxes with 232 and 520 molecules, respectively. Molecular dynamics (MD) simulations consisted of 1000000 steps of 0.0005 ps temporal increment after previous 50000 NVT-MC cycles for initialization followed by 100000 NVE-MC equilibration cycles. 

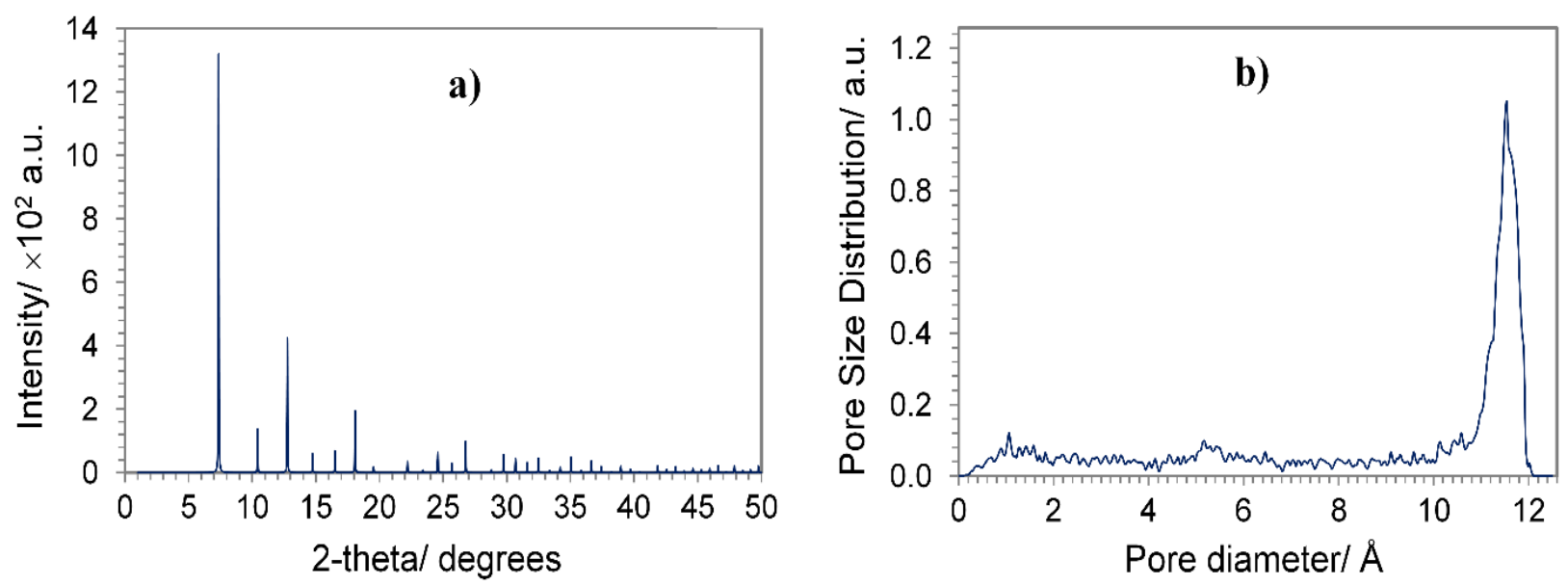

Figure S7. a) Powder X-ray diffraction (PXRD) pattern, and b) pore size distribution (PSD) of the ZIF-8 framework, calculated in this work for the ZIF-8P model.
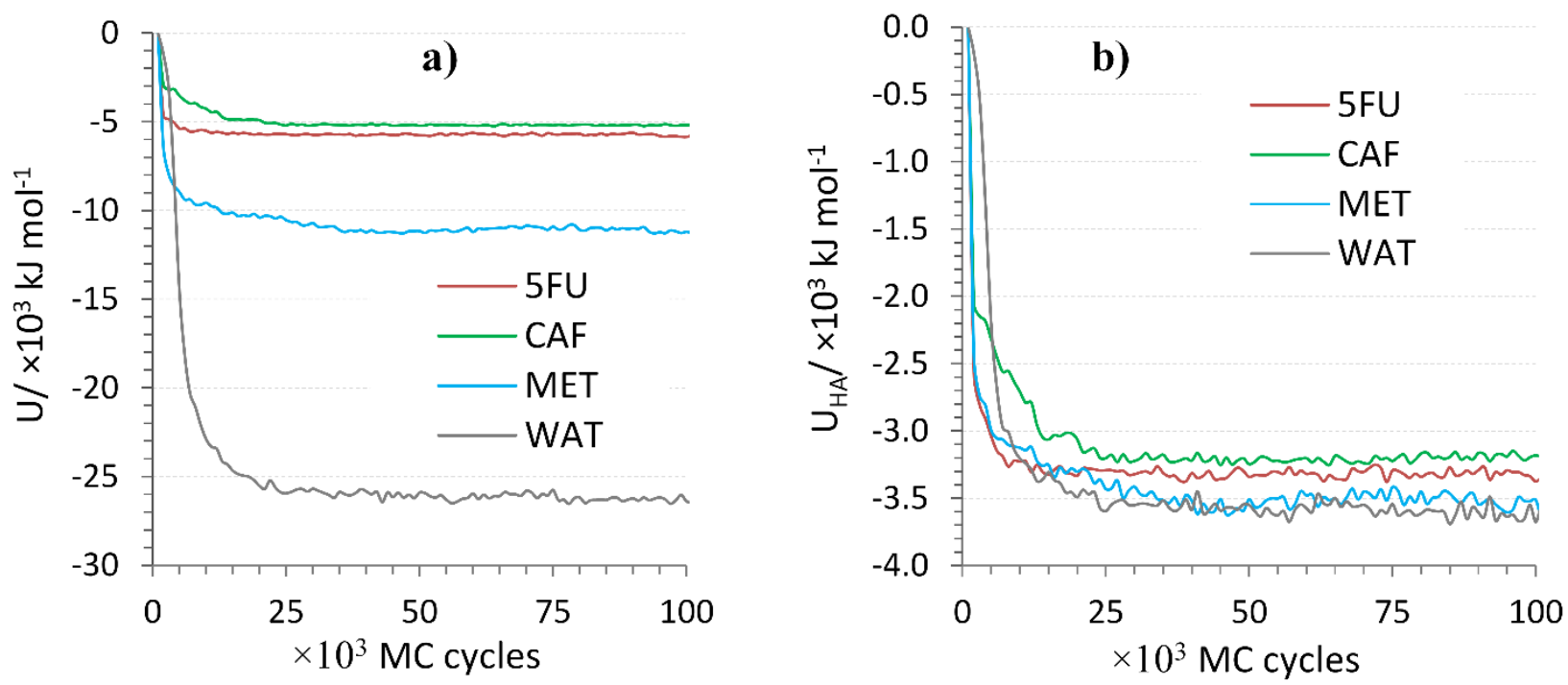

Figure S8. Results for the adsorption of the pure drugs and solvents in ZIF-8P. a) Total internal energy, U; and b) host-adsorbate energy, $\mathrm{U}_{\mathrm{HA}}$; in the adsorbed phase along the MC cycles in GCMC calculations. 5FU = 5-fluorouracil, $\mathrm{CAF}=$ caffeine, $\mathrm{MET}=$ methanol, $\mathrm{WAT}=$ water. 


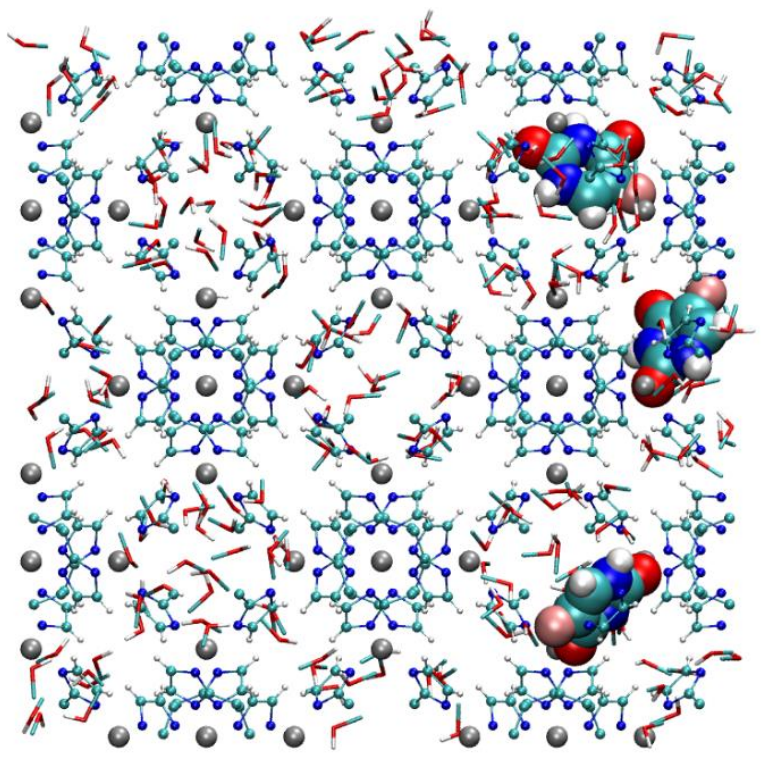

a)

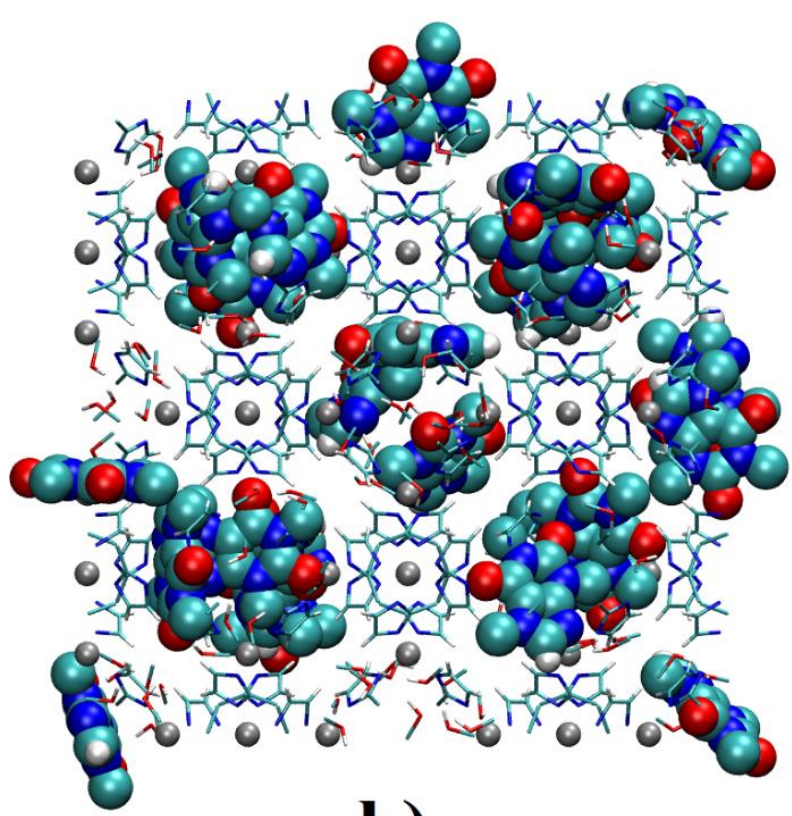

b)

Figure S9. Snapshots of stable configurations of ZIF-8P loaded with the drugs, taken from simulation of the adsorption on methanol solution at 0.30 mole fraction. a) 5FU and methanol. b) CAF and methanol. See Figure S1 for specific atom labels and Figure S2 for details of the ZIF-8P model.
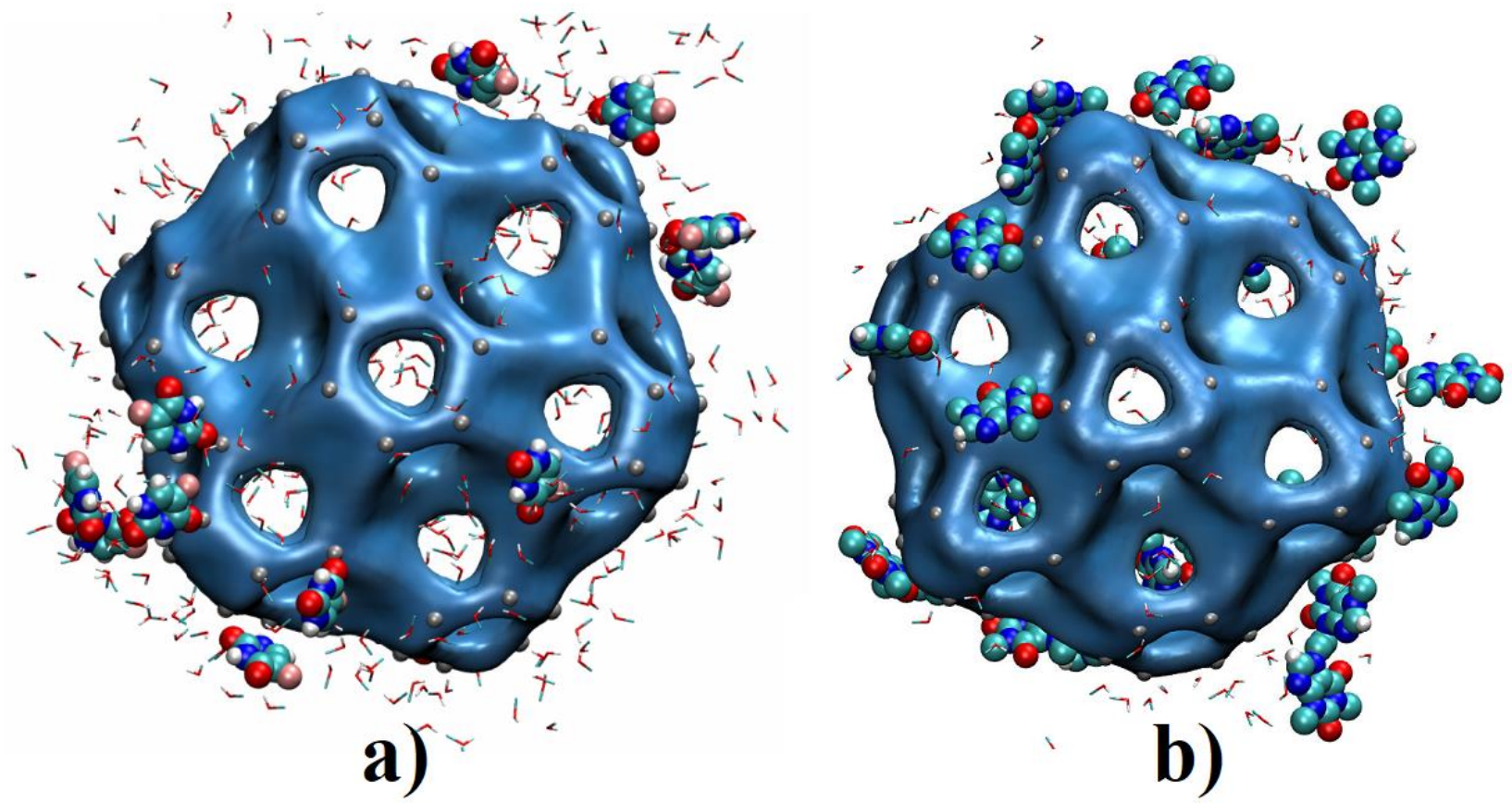

Figure S10. Snapshots of stable configurations of ZIF-8S loaded with the drugs, taken from simulation of the adsorption on methanol solution at 0.30 mole fraction. a) 5FU and methanol. b) CAF and methanol. See Figure $\mathrm{S} 1$ for specific atom labels and Figure S3 for details of the ZIF-8S model. 
Table S1. Summary of the crystallographic data of ZIF-8 used to construct the ZIF-8P and ZIF-8S models for the computer simulations. Reference CSD number 602542. ZIF-8P is the typical defect-free periodic ZIF-8, and ZIF-8S is a defect-containing ZIF-8 nano-crystal with missing linkers in the surface.

\begin{tabular}{ll}
\hline Empirical formula & $\mathrm{C}_{24} \mathrm{H}_{30} \mathrm{~N}_{12} \mathrm{O}_{10} \mathrm{Zn}_{3}$ \\
Crystal system & $\mathrm{Cubic}$ \\
Space group & $\mathrm{I}-43 m$ \\
Unit cell dimensions / orientations & $a=b=c=16.991 / \alpha=\beta=\gamma=90^{\circ}$ \\
Unit cell volume / surface area & $4905.2 \AA^{3} / 1947 \mathrm{~m}^{2} \mathrm{~g}^{-1}$ \\
Pore diameter / volume & $11.6 \AA / 0.663 \mathrm{~cm}^{3} \mathrm{~g}^{-1}$ \\
Density (calculated) & $1141 \mathrm{~kg} \mathrm{~m}^{3}$ \\
Crystal size & $0.16 \times 0.10 \times 0.10 \mathrm{~mm}^{3}$ \\
\hline
\end{tabular}

Table S2. Force filed parameters ( $\sigma$ and $\varepsilon$ ) and partial charges $(q)$ used to model the non-bonded interactions of the frameworks, drugs and solvents. All interactions were described by using the 12-6 Lennard-Jones (L-J) plus Coulomb potential.

\begin{tabular}{|c|c|c|c|c|}
\hline Atom $^{\text {a) }}$ & $\sigma(\AA)$ & $\varepsilon / \mathrm{k}_{\mathrm{B}}(\mathrm{K})$ & $\mathrm{q}(\mathrm{e})$ & \\
\hline $\mathrm{C} 1 ; \mathrm{C} 2$ & 3.473 & 47.856 & $0.119102 ;-0.001740$ & \multirow{5}{*}{ ZIF-8P } \\
\hline $\mathrm{C} 3 \mathrm{~m}$ & 3.760 & 108.000 & -0.137110 & \\
\hline $\mathrm{H} 2$ & 2.846 & 7.649 & -0.006211 & \\
\hline N1 & 3.263 & 38.949 & -0.290253 & \\
\hline Zn1 & 2.462 & 62.399 & 1.179139 & \\
\hline $\mathrm{C} 1 ; \mathrm{C} 2$ & 3.473 & 47.856 & $0.114751 ;-0.007464$ & \multirow{5}{*}{ ZIF-8S } \\
\hline $\mathrm{C} 3 \mathrm{~m}$ & 3.760 & 108.000 & -0.160237 & \\
\hline $\mathrm{H} 2$ & 2.846 & 7.649 & -0.002982 & \\
\hline N1 & 3.263 & 38.949 & -0.298105 & \\
\hline Zn1; Zn2 & 2.462 & 62.399 & $1.178931 ; 1.140126$ & \\
\hline $\mathrm{C} 1 ; \mathrm{C} 2 ; \mathrm{C} 3 ; \mathrm{C} 4$ & 3.473 & 47.856 & $0.834676 ; 0.008957 ; 0.049386 ; 0.725027$ & \multirow{5}{*}{$5 \mathrm{FU}$} \\
\hline $\mathrm{H} 1 ; \mathrm{H} 2 ; \mathrm{H} 3$ & 2.846 & 7.649 & $0.373104 ; 0.359151 ; 0.178344$ & \\
\hline N1; N2 & 3.263 & 38.949 & $-0.660413 ;-0.523581$ & \\
\hline $\mathrm{O} 1 ; \mathrm{O} 2$ & 3.033 & 48.158 & $-0.605434 ;-0.546527$ & \\
\hline F1 & 3.093 & 36.483 & -0.192689 & \\
\hline $\mathrm{C} 1 ; \mathrm{C} 2 ; \mathrm{C} 3 ; \mathrm{C} 4 ; \mathrm{C} 5$ & 3.473 & 47.856 & $0.578912 ;-0.276679 ; 0.663211 ; 0.694462 ; 0.296$ & \multirow{5}{*}{ CAF } \\
\hline H1 & 2.846 & 7.649 & 0.174114 & \\
\hline N1; N2; N3; N4 & 3.263 & 38.949 & $-0.681407 ;-0.114062 ;-0.404394 ;-0.372781$ & \\
\hline C6m; C7m; C8m & 3.760 & 108.000 & $0.211770 ; 0.320310 ; 0.275099$ & \\
\hline $\mathrm{O} 1 ; \mathrm{O} 2$ & 3.033 & 48.158 & $-0.690744 ;-0.674557$ & \\
\hline Ow & 3.151 & 76.678 & -0.8340 & \multirow[t]{2}{*}{ Water } \\
\hline $\mathrm{Hw}$ & 0.400 & 23.186 & 0.4170 & \\
\hline $\mathrm{Cm}$ & 3.650 & 110.450 & 0.1546 & \multirow[t]{3}{*}{ Methanol } \\
\hline $\mathrm{Om}$ & 3.166 & 97.775 & -0.6544 & \\
\hline $\mathrm{Hm}$ & none & none & 0.4998 & \\
\hline
\end{tabular}

a) See Figure S1 for identifying atom labels. 
Table S3. Results from GCMC simulations of the adsorption of the pure drugs and solvents in ZIF-8P. Left to right: the loadings $(\mathrm{L})$ in molec. cell ${ }^{-1}$ and $\mathrm{mg} \mathrm{g}^{-1}$; the total internal energy (U) and the host-adsorbate interaction energy $\left(\mathrm{U}_{\mathrm{HA}}\right)$ in the adsorbed phase, in units of $10^{3} \mathrm{~kJ} \mathrm{~mol}^{-1}$; the percentage fraction of $\mathrm{U}_{\mathrm{HA}}$ in $\mathrm{U}$, expressed as $\mathrm{R}_{\mathrm{HA}}=100 \times \mathrm{U}_{\mathrm{HA}} / \mathrm{U}$ in \%; and the enthalpy of adsorption $\left(\mathrm{H}_{\mathrm{ads}}\right)$ in $\mathrm{kJ} \mathrm{mol}^{-1}$.

\begin{tabular}{rrrrrrr}
\hline & $\begin{array}{r}\mathbf{L} / \\
\text { molec. cell }\end{array}$ & $\begin{array}{r}\mathbf{L} / \\
\mathrm{mg} \mathrm{g}^{-1}\end{array}$ & $\begin{array}{r}\mathbf{U} / \\
\times 10^{3} \mathrm{~kJ} \mathrm{~mol}^{-1}\end{array}$ & $\begin{array}{r}\mathbf{U}_{\mathbf{H A}} / \\
\times 10^{3} \mathrm{~kJ} \mathrm{~mol}^{-1}\end{array}$ & $\begin{array}{r}\mathbf{R}_{\mathbf{H A}} / \\
\%\end{array}$ & $\begin{array}{r}\mathbf{H}_{\text {ads }} / \\
\mathrm{kJ} \mathrm{mol}^{-1}\end{array}$ \\
\cline { 2 - 7 } 5FU & $80 \pm 1$ & $477 \pm 4$ & $-5.7 \pm 0.1$ & $-3.3 \pm 0.0$ & 58 & $-134.8 \pm 9.6$ \\
CAF & $47 \pm 1$ & $422 \pm 9$ & $-5.1 \pm 0.2$ & $-3.2 \pm 0.1$ & 62 & $-126.0 \pm 8.1$ \\
MET & $251 \pm 10$ & $369 \pm 14$ & $-11.3 \pm 0.6$ & $-3.5 \pm 0.1$ & 31 & $-46.8 \pm 7.0$ \\
WAT & $623 \pm 15$ & $514 \pm 13$ & $-26.0 \pm 0.8$ & $-3.6 \pm 0.1$ & 14 & $-46.9 \pm 8.4$ \\
\hline
\end{tabular}

5FU $=5$-fluorouracil, $\mathrm{CAF}=$ caffeine; $\mathrm{MET}=$ methanol, WAT $=$ water.

Table S4. Number of the drug molecules and of methanol molecules used for simulating the adsorption of the drugs in solution, via GEMC simulations, at mole fraction of the drug in the 0.01 to 0.30 range. ${ }^{\text {a) }}$

\begin{tabular}{|c|c|c|c|c|}
\hline \multirow{2}{*}{$\begin{array}{r}\text { Mole fraction } \\
x\end{array}$} & \multicolumn{2}{|c|}{$5 \mathrm{FU}$ solutions in $\mathrm{S}_{1}$} & \multicolumn{2}{|c|}{ CAF solutions in $S_{1}$} \\
\hline & 5FU molec. & MET molec. & CAF molec. & MET molec. \\
\hline 0.01 & 18 & 1826 & 18 & 1790 \\
\hline 0.02 & 37 & 1793 & 35 & 1723 \\
\hline 0.03 & 54 & 1759 & 51 & 1660 \\
\hline 0.04 & 72 & 1727 & 67 & 1600 \\
\hline 0.05 & 89 & 1695 & 81 & 1544 \\
\hline 0.06 & 106 & 1663 & 95 & 1490 \\
\hline 0.08 & 139 & 1602 & 121 & 1389 \\
\hline 0.10 & 171 & 1542 & 144 & 1298 \\
\hline 0.15 & 247 & 1401 & 194 & 1102 \\
\hline 0.20 & 317 & 1270 & 235 & 942 \\
\hline 0.25 & 383 & 1148 & 270 & 809 \\
\hline 0.30 & 444 & 1035 & 298 & 696 \\
\hline
\end{tabular}

${ }^{\text {a) }} \mathrm{S}_{1}$ is a $50 \times 50 \times 50 \AA$ cubic box, which contains the bulk fluid phase for estimating the adsorption via GEMC simulations, i.e., methanol solutions with the drugs at the mole-fractions in this table. The drugs are 5FU $=5$ fluorouracil and $\mathrm{CAF}=$ caffeine; and the solvent is MET = methanol. 
Table S5. Results from GEMC simulations of the adsorption of the drugs onto ZIF-8P from solution at several mole fractions $x$ (0.01 to 0.30). Left to right: the loadings (L) for the drug (and methanol in parenthesis) in molec. cell ${ }^{-1}$ and $\mathrm{mg} \mathrm{g}^{-1}$; the total internal energy $(\mathrm{U})$ and the host-adsorbate energy $\left(\mathrm{U}_{\mathrm{HA}}\right)$ in the adsorbed phase, in units of $10^{3} \mathrm{~kJ} \mathrm{~mol}^{-1}$; the percentage fraction of $\mathrm{U}_{\mathrm{HA}}$ in $\mathrm{U}$, expressed as $\mathrm{R}_{\mathrm{HA}}=100 \times \mathrm{U}_{\mathrm{HA}} / \mathrm{U}$ in $\%$; and the enthalpy of adsorption $\left(\mathrm{H}_{\mathrm{ads}}\right)$ in $\mathrm{kJ} \mathrm{mol}^{-1}$.

\begin{tabular}{|c|c|c|c|c|c|c|c|}
\hline & $x$ & molec. $\begin{array}{r}\mathbf{L} / \\
\text { cell }\end{array}$ & $\begin{array}{r}\mathbf{L} / \\
\mathrm{mg} \mathrm{g}^{-1}\end{array}$ & $\times 10^{3} \mathrm{~kJ} \mathrm{~mol}^{-1}$ & $\begin{array}{r}\mathbf{U}_{\mathbf{H A}} / \\
\times 10^{3} \mathrm{~kJ} \mathrm{~mol}^{-1}\end{array}$ & $\begin{array}{r}\mathbf{R}_{\mathbf{H A}} / \\
\%\end{array}$ & $\begin{array}{r}\mathbf{H}_{\text {ads }} / \\
\mathrm{kJ} \mathrm{mol}^{-1}\end{array}$ \\
\hline \multirow[t]{13}{*}{$5 \mathrm{FU}$} & 0.01 & $3 \pm 1(224 \pm 11)$ & $18 \pm 6(329 \pm 17)$ & $-10.0 \pm 0.7$ & $-3.1 \pm 0.2$ & 31 & $-46.4 \pm 7.2$ \\
\hline & 0.02 & $2 \pm 1(223 \pm 10)$ & $12 \pm 6(328 \pm 15)$ & $-9.9 \pm 0.6$ & $-3.1 \pm 0.2$ & 31 & $-51.0 \pm 4.5$ \\
\hline & 0.03 & $3 \pm 1(218 \pm 9)$ & $18 \pm 6(320 \pm 13)$ & $-9.6 \pm 0.9$ & $-3.0 \pm 0.3$ & 31 & $-46.1 \pm 9.4$ \\
\hline & 0.04 & $2 \pm 1(219 \pm 8)$ & $12 \pm 6(321 \pm 12)$ & $-9.7 \pm 0.4$ & $-3.0 \pm 0.1$ & 31 & $-47.6 \pm 6.2$ \\
\hline & 0.05 & $4 \pm 1(224 \pm 7)$ & $24 \pm 6(329 \pm 11)$ & $-10.0 \pm 0.5$ & $-3.1 \pm 0.1$ & 31 & $-44.9 \pm 5.6$ \\
\hline & 0.06 & $3 \pm 1(223 \pm 8)$ & $18 \pm 6(327 \pm 12)$ & $-9.9 \pm 0.7$ & $-3.1 \pm 0.2$ & 31 & $-47.9 \pm 9.4$ \\
\hline & 0.08 & $5 \pm 1(222 \pm 10)$ & $30 \pm 6(325 \pm 15)$ & $-9.9 \pm 0.7$ & $-3.1 \pm 0.2$ & 31 & $-54.3 \pm 4.0$ \\
\hline & 0.10 & $3 \pm 1(223 \pm 5)$ & $18 \pm 6(327 \pm 7)$ & $-9.9 \pm 0.8$ & $-3.1 \pm 0.2$ & 31 & $-47.8 \pm 6.8$ \\
\hline & 0.15 & $4 \pm 1(219 \pm 8)$ & $24 \pm 6(321 \pm 12)$ & $-9.7 \pm 0.5$ & $-3.0 \pm 0.1$ & 31 & $-49.3 \pm 5.4$ \\
\hline & 0.20 & $5 \pm 1(219 \pm 7)$ & $30 \pm 6(321 \pm 10)$ & $-9.7 \pm 0.9$ & $-3.0 \pm 0.3$ & 31 & $-49.9 \pm 5.4$ \\
\hline & 0.25 & $3 \pm 1(214 \pm 8)$ & $18 \pm 6(315 \pm 12)$ & $-9.6 \pm 0.5$ & $-3.0 \pm 0.1$ & 31 & $-47.2 \pm 9.5$ \\
\hline & 0.30 & $4 \pm 1(211 \pm 8)$ & $24 \pm 6(310 \pm 12)$ & $-9.3 \pm 1.0$ & $-2.9 \pm 0.3$ & 31 & $-52.6 \pm 8.5$ \\
\hline & $\overline{A v .}{ }^{\text {a) }}$ & $3 \pm 1(220 \pm 8)$ & $20 \pm 6(323 \pm 12)$ & $-9.8 \pm 0.7$ & $-3.1 \pm 0.2$ & 31 & $-48.7 \pm 6.8$ \\
\hline \multirow[t]{13}{*}{$\overline{\mathrm{CAF}}$} & 0.01 & $23 \pm 1(138 \pm 8)$ & $204 \pm 9(203 \pm 12)$ & $-9.5 \pm 0.5$ & $-3.4 \pm 0.1$ & 36 & $-54.2 \pm 9.6$ \\
\hline & 0.02 & $25 \pm 3(135 \pm 9)$ & $222 \pm 23(198 \pm 13)$ & $-9.6 \pm 0.7$ & $-3.5 \pm 0.2$ & 37 & $-55.2 \pm 9.2$ \\
\hline & 0.03 & $22 \pm 2(151 \pm 11)$ & $196 \pm 18(221 \pm 16)$ & $-10.0 \pm 0.8$ & $-3.5 \pm 0.2$ & 35 & $-51.7 \pm 5.6$ \\
\hline & 0.04 & $22 \pm 1(150 \pm 11)$ & $196 \pm 9(220 \pm 17)$ & $-10.0 \pm 0.6$ & $-3.5 \pm 0.2$ & 35 & $-54.4 \pm 8.0$ \\
\hline & 0.05 & $23 \pm 2(142 \pm 9)$ & $204 \pm 18(208 \pm 13)$ & $-9.7 \pm 0.6$ & $-3.5 \pm 0.1$ & 36 & $-56.5 \pm 6.1$ \\
\hline & 0.06 & $23 \pm 1(140 \pm 12)$ & $204 \pm 9(205 \pm 18)$ & $-9.6 \pm 0.7$ & $-3.5 \pm 0.2$ & 36 & $-54.2 \pm 4.0$ \\
\hline & 0.08 & $24 \pm 2(139 \pm 8)$ & $213 \pm 18(204 \pm 12)$ & $-9.7 \pm 0.5$ & $-3.5 \pm 0.1$ & 36 & $-53.1 \pm 6.7$ \\
\hline & 0.10 & $23 \pm 1(141 \pm 9)$ & $204 \pm 9(207 \pm 13)$ & $-9.7 \pm 0.5$ & $-3.5 \pm 0.2$ & 36 & $-52.4 \pm 5.1$ \\
\hline & 0.15 & $24 \pm 2(142 \pm 8)$ & $213 \pm 18(208 \pm 12)$ & $-9.9 \pm 0.8$ & $-3.6 \pm 0.2$ & 36 & $-53.0 \pm 5.4$ \\
\hline & 0.20 & $24 \pm 2(134 \pm 7)$ & $213 \pm 18(197 \pm 10)$ & $-9.4 \pm 0.6$ & $-3.4 \pm 0.2$ & 36 & $-55.0 \pm 3.7$ \\
\hline & 0.25 & $26 \pm 3(129 \pm 8)$ & $231 \pm 22(190 \pm 12)$ & $-9.5 \pm 0.6$ & $-3.5 \pm 0.1$ & 37 & $-49.7 \pm 5.4$ \\
\hline & 0.30 & $25 \pm 2(131 \pm 6)$ & $222 \pm 18(193 \pm 9)$ & $-9.3 \pm 0.4$ & $-3.4 \pm 0.1$ & 37 & $-49.2 \pm 4.6$ \\
\hline & $\overline{\mathrm{Av} .}{ }^{\text {a) }}$ & $24 \pm 2(139 \pm 9)$ & $210 \pm 16(204 \pm 13)$ & $-9.7 \pm 0.6$ & $-3.5 \pm 0.2$ & 36 & $-53.2 \pm 6.4$ \\
\hline
\end{tabular}

a) Average over the values for each mole-fraction.

Table S6. Results from GEMC simulations of the adsorption of the drugs onto ZIF-8S from methanol solution at mole fraction 0.30 . The simulations were performed by blocking the entrance of the drugs into the inner pores of the framework. Left to right: the loadings (L) for the drug (and methanol in parenthesis) in molec. cell $^{-1}$ and $\mathrm{mg} \mathrm{g}^{-1}$; the total internal energy $(\mathrm{U})$ and the host-adsorbate energy $\left(\mathrm{U}_{\mathrm{HA}}\right)$ in the adsorbed phase, in units of $10^{3} \mathrm{~kJ} \mathrm{~mol}^{-1}$; the percentage fraction of $\mathrm{U}_{\mathrm{HA}}$ in $\mathrm{U}$, expressed as $\mathrm{R}_{\mathrm{HA}}=100 \times \mathrm{U}_{\mathrm{HA}} / \mathrm{U}$ in $\%$; and the enthalpy of adsorption $\left(\mathrm{H}_{\mathrm{ads}}\right)$ in $\mathrm{kJ} \mathrm{mol}^{-1}$.

\begin{tabular}{|c|c|c|c|c|c|c|}
\hline & molec. cell $^{-1}$ & $\begin{array}{r}\mathbf{L} / \\
\mathrm{mg} \mathrm{g}^{-1}\end{array}$ & $\times 10^{3} \mathrm{~kJ} \mathrm{~mol}^{-1}$ & $\begin{array}{r}\mathbf{U}_{\mathbf{H A}} / \\
\times 10^{3} \mathrm{~kJ} \mathrm{~mol}^{-1}\end{array}$ & $\begin{array}{r}\mathbf{R}_{\mathbf{H A}} / \\
\%\end{array}$ & $\begin{array}{r}\mathbf{H}_{\text {ads }} / \\
\mathrm{kJ} \mathrm{mol}^{-1}\end{array}$ \\
\hline $5 \mathrm{FU}$ & $12 \pm 1(403 \pm 15)$ & $39 \pm 3(325 \pm 12)$ & $-25.1 \pm 1.2$ & $-11.7 \pm 0.3$ & 47 & $-49.3 \pm 7.1$ \\
\hline $\mathrm{CAF}$ & $30 \pm 2(205 \pm 8)$ & $146 \pm 10(166 \pm 6)$ & $-37.2 \pm 2.6$ & $-11.3 \pm 0.6$ & 30 & $-62.1 \pm 8.6$ \\
\hline
\end{tabular}


Table S7. Results from GEMC simulations of the desorption of the drugs from the ZIF-8P and ZIF-8S models. Left to right: the initial loading of the drugs $\left(\mathrm{L}_{0}\right)$ on the respective ZIF-8 model, in molec. cell ${ }^{-1}$; the final loading $\left(\mathrm{L}_{\mathrm{f}}\right)$ of the drug, in $\mathrm{mg} \mathrm{g}^{-1}$; the amount of drug released to the water bath (R), in $\mathrm{mg} \mathrm{g}^{-1}$ and wt.\%; and the loading of water into the framework $\left(\mathrm{Lw}_{\mathrm{w}}\right)$, in $\mathrm{mg} \mathrm{g}^{-1}$.

\begin{tabular}{lcccccc}
\hline & & $\mathbf{L}_{\mathbf{0}} / \mathrm{molec} \mathrm{cell}^{-1}$ & $\mathbf{L}_{\mathbf{f}} / \mathrm{mg} \mathrm{g}^{-1}$ & $\mathbf{R} / \mathrm{mg} \mathrm{g}^{-1}$ & $\mathbf{R} / \%$ & $\mathbf{L}_{\mathbf{w}} / \mathrm{mg} \mathrm{g}^{-1}$ \\
\hline ZIF-8P & $5 \mathrm{FU}$ & 80 & $208 \pm 24$ & 269 & 56.3 & $42 \pm 3$ \\
& $\mathrm{CAF}$ & 47 & $248 \pm 27$ & 170 & 40.6 & $60 \pm 5$ \\
\hline ZIF-8P & $5 \mathrm{FU}$ & 3 & $0 \pm 6$ & 18 & 100.0 & $145 \pm 14$ \\
& $\mathrm{CAF}$ & 24 & $178 \pm 9$ & 36 & 16.7 & $240 \pm 17$ \\
\hline ZIF-8S & 5FU & 12 & $33 \pm 3$ & 6 & 16.3 & $125 \pm 9$ \\
& $\mathrm{CAF}$ & 30 & $132 \pm 7$ & 15 & 10.0 & $135 \pm 12$ \\
\hline
\end{tabular}

${ }^{\text {a) }} \mathrm{S}_{0}$ contains the respective ZIF-8 model plus $\mathrm{L}_{0}$ molecules of the drug; and $\mathrm{S}_{1}$ is a $30 \times 30 \times 30 \AA$ cubic box with initially 899 molecules of water.

Equation S1. Expression used to approximate the change in the potential energy of the system $(U)$ upon adsorption of the guest molecules $(N)$,

$$
\left(\frac{\delta U}{\delta N}\right)_{V, T}=\frac{\langle U \times N\rangle_{\mu}-\langle U\rangle_{\mu}\langle N\rangle_{\mu}}{\left\langle N^{2}\right\rangle_{\mu}-\langle N\rangle_{\mu}\langle N\rangle_{\mu}}
$$

where $\langle\cdots\rangle_{\mu}$ refers to the configurational average at constant chemical potential $(\mu)$ during the simulation.

The enthalpy of adsorption is then calculated as

$$
\Delta H_{\mathrm{ads}}=\left(\frac{\delta U}{\delta N}\right)_{V, T}-\left\langle U_{\mathrm{g}}\right\rangle-k_{\mathrm{B}} T=\frac{\langle U \times N\rangle_{\mu}-\langle U\rangle_{\mu}\langle N\rangle_{\mu}}{\left\langle N^{2}\right\rangle_{\mu}-\langle N\rangle_{\mu}\langle N\rangle_{\mu}}-\left\langle U_{\mathrm{g}}\right\rangle-k_{\mathrm{B}} T
$$

where the $\left\langle U_{\mathrm{g}}\right\rangle$ was calculated as the average energy of a single guest molecule in the explicit reservoir $\mathrm{S}_{1}$ box (containing the fluid phase in the GEMC simulations); $k_{\mathrm{B}}$ is the Boltzmann constant and $T$ is the temperature of the system. 